\title{
The ICMR bulletin on targeted hydroxychloroquine prophylaxis for Covid-19: Need to interpret with caution
}

\section{MIGITA D'CRUZ}

\section{Abstract}

The National Task Force for Covid-19 of the Indian Council of Medical Research (ICMR) in a bulletin dated March 21, 2020 recommended the use of hydroxychloroquine for prophylaxis in asymptomatic health care workers caring for suspected or confirmed patients and household contacts of confirmed patients. This is cause for concern with regard to bioethics and good clinical practice.

The evidence for the efficacy of chloroquine and hydroxychloroquine is currently derived from open label trials and cell culture studies with no conclusive evidence available from randomised clinical trials. Hydroxychloroquine also carries contraindications in the case of conditions such as maculopathy, retinopathy and QTC prolongation and should be used with caution in vulnerable populations such as children, pregnancy, lactation and the elderly.

Despite this, there has been a rush to procure and self-medicate with hydroxy-chloroquine, which has been addressed by the National Task Force.

The WHO and the FDA have not found adequate evidence to recommend any specific medication for the treatment of Covid-19. While further evidence is awaited, including from trials registered with the FDA and the ICMR, it is recommended that the administration of hydroxychloroquine for chemo-prophylaxis be considered on a case by case basis with monitoring by a registered medical practitioner including electrocardiography (ECG). The potential for retinal and cardiac toxicity must also be borne in mind. It is further recommended that a public advisory regarding the need for caution in chemo-prophylaxis be made available in the public domain.

Keywords: coronavirus, Covid-19, SARS-CoV-2, hydroxychloroquine, chloroquine, chemoprophylaxis, bioethics, evidence-based medicine

The bulletin from the National Task Force for Covid-19 of the Indian Council of Medical Research (ICMR) dated March 21,2020 , recommends the use of hydroxychloroquine for prophylaxis in (i) asymptomatic healthcare workers involved in the care of suspected and confirmed patients and ii)

Author: Migita D'Cruz (migitadcruz@gmail.com), Senior Resident, Geriatric Clinic and Services, Department of Psychiatry, National Institute of Mental Health and Neurosciences (NIMHANS), Bengaluru, 56 0029, INDIA.

To cite: D'Cruz M. The ICMR bulletin on targeted hydroxychloroquine prophylaxis for COVID-19: Need to interpret with caution. Indian J Med Ethics. 2020 Apr-Jun; 5(2) NS: 100-2:DOI:10.20529/IJME.2020.040.

Peer Reviewer: An anonymous reviewer

(c) Indian Journal of Medical Ethics 2020 household contacts of confirmed patients, with the viral infection (1). This is a cause for concern, both with regard to bioethics and good clinical practice. The recommendation is based upon recent evidence of the repurposed anti-malarial drug, derived from preliminary studies, in the wake of the pandemic $(2,3,4)$.

Open label studies have demonstrated significantly better clinical outcomes and virus clearance rates in patients with confirmed Covid-19 infection (regardless of clinical status), when treated with hydroxychloroquine as opposed to controls. A combination of hydroxychloroquine and azithromycin appears to be superior in terms of both these outcomes, when compared to hydroxychloroquine alone (5).

Cell culture studies, in addition, have demonstrated reduced replication by the SARS-CoV- 2 in infected cell culture lines treated with hydroxychloroquine alone, and a combination of remdesivir and hydroxychloroquine (6).

The expert consensus derived from these preliminary studies is that hydroxychloroquine limits the replication of the SARSCoV-2 in vitro and improves clinical outcomes in vivo and recommends further clinical studies to explore its role in prophylaxis and treatment. As of April 4, 2020, there appear to be 60 registered ongoing clinical trials to evaluate the efficacy of hydroxychloroquine, across the world $(7,8,9,10)$. While this preliminary evidence is heartening, there is need for caution mixed with optimism.

Firstly, there is not, as yet, definitive pre-clinical or clinical evidence demonstrating the efficacy of hydroxychloroquine as a prophylactic agent for Covid-19 $(11,12)$. Sixteen to twenty percent of patients with the infection, may be asymptomatic $(5,13)$. However, transmission rates, though estimated to be high, are unclear. While asymptomatic patients may transmit up to $10 \%$ of the infection, it would be inappropriate to initiate treatment in the absence of definitive evidence of Covid-19 infection $(14,15)$.

Secondly, drug pharmacokinetics in special populations such as children (less than 12 years), the elderly; and expectant and lactating mothers differ considerably from the general population (16). They are also at greater risk of adverse effects due to hydroxychloroquine. Considering that special populations are at higher risk of developing any infection, the drug may be least applicable in patients where it is the most required (15). The logistic issues surrounding the conduct of research in these populations is acknowledged, as is the urgency for containment of the spread of the infection in the community (17). Despite this, the use of the drug, particularly in these subsets merits extreme caution, optimal dose titration and close monitoring. 
Thirdly, the drug is also contraindicated in patients at risk of, or suffering from retinopathy, maculopathy, glucose 6 phosphate deficiency and QTc prolongation (5). Azithromycin, when combined with hydroxychloroquine, appears to have a cumulative effect upon the QTc interval (5).The ICMR has not, in their bulletin addressed these contraindications or how to screen for them prior to drug administration.

The bulletin, meanwhile, has been interpreted, considerably out of context by both the healthcare profession and the lay population, several of whom appear to have procured the drug over the counter or with self-prescriptions and medicated themselves and contacts for prophylaxis. This has led to both the shortage of what is an essential medication for the treatment of malaria and auto-immune conditions, and to reports of maculopathy and cardiac arrest in vulnerable individuals (18).

The National Task Force for Covid-19 of the Indian Council of Medical Research (ICMR) has taken cognisance of the public rush to procure hydroxychloroquine in the wake of its initial notification. They have gone on to emphasise in a subsequent notice that the administration of hydroxychloroquine for chemo-prophylaxis for Covid-19 should not instil a false sense of security and recommended that the drug be prescribed only by a registered medical practitioner while the healthcare workers remain in home quarantine. The Task Force has also asked healthcare workers to follow all recommended public health measures, self-monitor their health and report to a registered medical practitioner if they become symptomatic (19). They are further initiating measures to regulate prescription and sales to curb self-administration (19).

However, the precautions that household contacts of confirmed patients must adopt during chemo-prophylaxis have not received a similar degree of attention, leaving the onus upon the registered medical practitioner treating confirmed patients to identify, quarantine and administer hydroxychloroquine as appropriate.

In this context, the death due to cardiac arrest, of a senior anaesthetist in Guwahati, reportedly after taking hydroxychloroquine is cause for concern, and reinforces the need for caution with chemo-prophylaxis (20)

Thus, there appears to be inadequate clinical evidence, as of now, to warrant the use of hydroxychloroquine for prophylaxis. Further, the risk-benefit ratio of drug administration needs to be closely examined, particularly in those vulnerable to adverse drug reactions. The clinical contraindications need to be made explicit in public health information, as must caution against self-administration. A better strategy may be to enhance testing of asymptomatic contacts and consider the administration of the hydroxychloroquine on a case by case basis, while awaiting results of the clinical trials that are underway (21).

Several large scale trials to evaluate the therapeutic and prophylactic potential of chloroquine and hydroxychloroquine for Covid-19 are under way, across the world, including those registered by the FDA and ICMR (22). In view of the gravity of the pandemic, trials have understandably been fast-tracked (23). While the results of these trials are to be awaited, it is important to note that there is preliminary evidence for continued cardiac risk, with a chloroquine trial in Brazil halted after some patients developed arrhythmia (24). Another open label, randomised clinical trial on hydroxychloroquine in China has not found higher negative conversion rate in patients with Covid-19 (25).

The WHO and the FDA have not found conclusive evidence to support the recommendation of any drug for the treatment or prophylaxis of Covid-19 and consider hydroxychloroquine experimental therapy. It is recommended that the administration of the drug, therefore, be considered with due regard for Section 12 of the ICMR guidelines for research during humanitarian emergencies and disasters and the Good Clinical Practice Guidelines for Clinical Research in India by the Central Drugs Standard Control Organization (CDSCO) $(26,27$, 28).

It is recommended that chemo-prophylaxis, if warranted, be conducted under careful supervision of a registered medical practitioner. An advisory regarding relative contraindications to hydroxychloroquine prophylaxis such as retinal disorders, cardiac disease and haemolytic anaemias (such as are associated with sickle cell anaemia and glucose 6 phosphate deficiency) should be made available to medical professionals and in the public domain. A baseline ECG to identify risk of QTc prolongation and other arrhythmias and repeat ECG while on chemo-prophylaxis would ensure adequate monitoring of potential adverse events. Medical practitioners should also bear in mind the potential for drug interactions, such as cumulative risk of QTc prolongation when combined with other antimicrobials and psychotropic medications. Care must particularly be taken with special populations, including children, expectant women, lactating mothers and the elderly $(29,30)$.

\section{Conflict of interest: None to declare}

\section{References}

1. National Task Force for Covid 19. Advisory on the use of Hydroxychloroquine as prophylaxis for SARS-CoV-2 infection. New Delhi: ICMR; 2020 March 22[cited 2020 Apr 14]. Available from: https://icmr.nic.in/sites/default/files/upload_documents/HCQ_ Recommendation_22March final MM V2.pdf

2. Harrison C. Coronavirus puts drug repurposing on the fast track. Nat Biotechnol.2020 Feb 27[cited 2020 Apr 14]. Available from:https://www. nature.com/articles/d41587-020-00003-1

3. Colson P, Rolain J-M, Lagier J-C, Brouqui P, Raoult D. Chloroquine and hydroxychloroquine as available weapons to fight COVID-19. Int J Antimicrob Agents. 2020 Mar 4[cited 2020 Apr 14]; 105932. Available from: https://www.ncbi.nlm.nih.gov/pubmed/32145363

4. Faccenda E, Armstrong JF, Davenport AP, Harding SD, Pawson AJ, Southan C, Davies JA. Coronavirus Information. IUPHAR/BPS Guide to Pharmacology. Date unknown [cited 2020 Apr 14]. Available from https://www.guidetopharmacology.org/coronavius.jsp

5. Gautret $P$, Lagier J-C, Parola $P$, Hoang VT, Meddeb L, Mailhe $M$, et al. Hydroxychloroquine and azithromycin as a treatment of COVID-19: results of an open-label non-randomized clinical trial. Int J Antimicrob 
Agents. 2020 Mar 20 [cited 2020 Apr 14]. 105949. Available from: https:// www.sciencedirect.com/science/article/pii/S0924857920300996

6. Wang M, Cao R, Zhang L, Yang X, Liu J, Xu M, et al. Remdesivir and chloroquine effectively inhibit the recently emerged novel coronavirus (2019-nCoV) in vitro. Cell Res.2020 Mar [cited 2020 Apr 15];30(3):269-71. Available from: https://www.nature.com/articles/s41422-020-0282-0

7. Shah S, Das S, Jain A, Misra DP, Negi VS. A systematic review of the prophylactic role of chloroquine and hydroxychloroquine in Coronavirus Disease-19 (COVID-19). Int J Rheum Dis. 2020 Apr 13[cited 2020 Apr 16]. Available from: https://onlinelibrary.wiley.com/doi/abs/10.1111/1756185X.13842

8. Cortegiani A, Ingoglia G, Ippolito M, Giarratano A, Einav S. A systematic review on the efficacy and safety of chloroquine for the treatment of COVID-19. J Crit Care. 2020 Mar 10 [cited 2020 Apr 15]. Available from: http://www.sciencedirect.com/science/article/pii/S0883944120303907

9. Leask H. Huge global push for clinical trials in Covid-19. Medscape. 2020Apr 4[cited 2020 Apr 16]. Available from: http://www.medscape. com/viewarticle/928094

10. Expert consensus on chloroquine phosphate for the treatment of novel coronavirus pneumonia. Multicentre collaboration group of Department of Science and Technology of Guangdong Province and Health Commission of Guangdong Province for chloroquine in the treatment of novel coronavirus pneumonia. Zhonghua Jie He He Hu Xi Za Zhi [Chinese Journal of Tuberculosis and Respiratory Diseases]. 2020 Mar 12[cited 2020 Apr 15]; 43(3):185-8; Available from: https://www.ncbi. nlm.nih.gov/pubmed/32164085

11. Centers for Disease Control and Prevention. Coronavirus Disease 2019 (COVID-19).CDC. 2020 [cited 2020 Mar 25]. Available from: https://www. cdc.gov/coronavirus/2019-ncov/hcp/therapeutic-options.html

12. World Health Organization. Coronavirus disease (COVID-19) technical guidance: Patient management. Geneva: WHO;2019 [cited 2020 Apr 15]. Available from: https://www.who.int/emergencies/diseases/novelcoronavirus-2019/technical-guidance/patient-management

13. Mizumoto K, Kagaya K, Zarebski A, Chowell G. Estimating the asymptomatic proportion of coronavirus disease 2019 (COVID-19) cases on board the Diamond Princess cruise ship, Yokohama, Japan, 2020. Euro Surveill. 2020 Mar 12[cited 2020 Apr 15]. Available from: https://www.eurosurveillance.org/content/10.2807/1560-7917. ES.2020.25.10.2000180

14. Coronavirus spreads quickly and sometimes before people have symptoms, study finds. UT News. 2020 March 16 [cited 2020 Apr 15]. Available from: https://news.utexas.edu/2020/03/16/coronavirusspreads-quickly-and-sometimes-before-people-have-symptomsstudy-finds/

15. Berger ZD, Evans NG, Phelan AL, Silverman RD. Covid-19: control measures must be equitable and inclusive. BMJ.2020 Mar 20[cited 2020 Apr 15]; 368. Available from: https://www.bmj.com/content/368/bmj. $\mathrm{m} 1141$

16. World Health Organisation. Guidelines for the treatment of malaria. 3rd edition. Geneva: WHO; 2015 Apr [cited 2020 Apr 16]. Available from: https://www.who.int/malaria/publications/atoz/9789241549127/en/

17. Hare SS, Rodrigues J, Nair A, Robinson G. Lessons from the frontline of the covid-19 outbreak. BMJ.blog 2020[cited 2020 Apr 16]. Available from: https://blogs.bmj.com/bmj/2020/03/20/lessons-from-the-frontline-of- the-covid-19-outbreak/

18. Sehgal M. Pharmacists blame Donald Trump for shortage of hydroxychloroquine. India Today. 2020 Mar 24[cited 2020 Apr 14]. Available from: https://www.indiatoday.in/india/story/ pharmacists-blame-donald-trump-for-shortage-of-hydroxychloroqui ne-1659312-2020-03-24

19. Indian Council of Medical Research. Advisory on the use of Hydroxychloroquine as prophylaxis for SARS-CoV-2 infection. New Delhi: ICMR;2020 Mar 23. Available from: https://www.mohfw.gov.in/pdf/

20. Nath HK. Coronavirus in India: Guwahati doctor dies after allegedly taking hydroxychloroquine. India Today. 2020 Mar 30[cited 2020 Apr 14]. Available from: https://www.indiatoday.in/india/story/coronavirusin-india-guwahati-doctor-dies-after-allegedly-taking-hydroxychloroqu ine-1661535-2020-03-30

21. Watkins J. Preventing a covid-19 pandemic. BMJ. 2020 Feb 28; 368. Available from: https://www.bmj.com/content/368/bmj.m810

22. Hydroxychloroquine Post Exposure Prophylaxis for Coronavirus Disease (COVID-19) - Full Text View - ClinicalTrials.gov. Available from: https:// clinicaltrials.gov/ct2/show/NCT04318444

23. Global trial fast tracks testing of hydroxychloroquine, other COVID-19 therapies.. Science Daily. 2020 Apr 9 [cited 2020 Apr 14]. Available from: https://www.sciencedaily.com/releases/2020/04/200409140015.htm

24. Thomas K, Sheikh K. Small chloroquine study halted over risk of fatal heart complications. New York Times. 2020 Apr 12[cited 2020 Apr 15]. Available from: https://www.nytimes.com/2020/04/12/health/ chloroquine-coronavirus-trump.html

25. Tang W, Cao Z, Han M, Wang Z, Chen J, Sun W, et al. Hydroxychloroquine in patients with COVID-19: an open-label, randomized, controlled trial. medRxiv. 2020 Apr 14 (preprint) [cited 2020 Apr 16]. Available from: https://www.medrxiv.org/content/10.1101/2020.04.10.20060558v1

26. Indian Council of Medical Research. National Ethical Guidelines for Biomedical and Health Research involving Human Participants. New Delhi: ICMR; 2017 Oct [cited 2020 Apr 15]. Available from: https:// www.icmr.nic.in/sites/default/files/guidelines/ICMR_Ethical_ Guidelines_2017.pdf

27. Central Drugs Standard Control Organization. Good Clinical Practice Guidelines for Clinical Research in India. New Delhi: CDSCO; 2001 [cited 2020 Apr 16]. Available from: http://www.sgpgi.ac.in/sop/GCP-\%20 Indian.pdf

28. Dunn A. Why experts are skeptical of studies that seemed to show promising results from using a decades-old malaria drug to treat the coronavirus. Business Insider. 2020 Apr 8 [cited 2020 Apr 16]. Available from: https://www.businessinsider.in/science/news/why-expertsare-skeptical-of-studies-that-seemed-to-show-promising-resultsfrom-using-a-decades-old-malaria-drug-to-treat-the-coronavirus/ articleshow/75049509.cms

29. Prescriber's Digital Reference. Hydroxychloroquine sulfate: Drug Summary. PDR.net. date unknown [cited 2020 Apr 16]. Available from: https://www.pdr.net/drug-summary/Plaquenil-hydroxychloroquinesulfate-1911

30. Ferner RE, Aronson JK.Chloroquine and hydroxychloroquine in covid-19. BMJ. 2020 Apr 8[cited 2020 Apr 16]; 369.m1432. Available from: https:// www.bmj.com/content/369/bmj.m1432 